\title{
Spatial Distribution and Associated Risk Factors of Soil-Transmitted Helminth Infection in a Semi-urban Community in Southwest Nigeria
}

\author{
Oluwatoba Olufunke Abiodun ${ }^{1, *}$, Taiwo Olalekan John², Nwuba Roseangela Ifeyinwa ${ }^{3}$ \\ ${ }^{1}$ Department of Medical Microbiology and Parasitology, Faculty of Basic Medical Science, College of Medicine, University of Ibadan, \\ Ibadan, Nigeria \\ ${ }^{2}$ Geographical Information System Unit, Department of Geography, Faculty of Social Sciences, University of Ibadan, Ibadan, Nigeria \\ ${ }^{3}$ Cellular Parasitology Programme, Cell Biology and Genetic Unit, Department of Zoology, Faculty of Science, University of Ibadan, Ibadan, \\ Nigeria
}

\author{
Email address: \\ ooluwatoba@cartafrica.org (O. O. Abiodun), oluwatobang@yahoo.com (O. O. Abiodun) \\ ${ }^{*}$ Corresponding author
}

\section{To cite this article:}

Oluwatoba Olufunke Abiodun, Taiwo Olalekan John, Nwuba Roseangela Ifeyinwa. Spatial Distribution and Associated Risk Factors of SoilTransmitted Helminth Infection in a Semi-urban Community in Southwest Nigeria. Journal of Health and Environmental Research.

Vol. 7, No. 4, 2021, pp. 185-191. doi: 10.11648/j.jher.20210704.13

Received: September 21, 2021; Accepted: October 14, 2021; Published: October 28, 2021

\begin{abstract}
Parasite distribution exhibit heterogeneity within households and communities. The aim of this study is to identify the spatial distribution, clustering and associated risk factors of Soil-transmitted Helminths infection in a semi-urban area in Southwest Nigeria. Geographical information System (GIS) was used to map the town into three density areas; low, medium and high density areas. Two hundred and thirty six soil samples were obtained from the surroundings of 137 households and stool samples were collected from the inhabitant of the households. Moran index was used to analyze the spatial distribution of STH within the community. A total of 137 households were sampled for human STH and environmental soil samples from the household were analyzed. The prevalence of human STH infection was $41.7 \%$ while that of soil parasite was $27.7 \%$ within the selected household. Ascaris lumbricoides was the predominant STH infection in the community sampled with $24.1 \%$ prevalence followed by Hookworm. Spatial analysis showed that $A$. lumbricoides infection was significantly clustered only in the GIS mapped medium density area of Igbo-Ora ( $\mathrm{z}$-score $2.302, \mathrm{p}=0.021$ ), while hookworm infection was randomly distributed in all the GIS mapped areas of Igbo-Ora. There was a statistically significant association between human STH infection and presence of parasite in the household soil $\left(x^{2} 5.74, p\right.$-value 0.017$)$. None of the risk factors evaluated was found to have significant association for the clustering pattern of infection found in the medium density area of the community. Meanwhile, factors such as; the physical presence of a popularly patronized local market in the area, lack of any visible public toilet and the use of bushes around the area by the people for defecation contribute to the reasons for the clustering of the Ascaris infection. Also, the ability of Ascaris to withstand environmental conditions than other STH parasite may contribute to the pattern observed. The differences in the pattern of distribution and associated risk factors revealed that environmental conditions and exposure factors are major determinant of STH infection.
\end{abstract}

Keywords: Soil-transmitted Helminths, Spatial Clustering, Density Areas, Ascaris lumbricoides, Hookworm

\section{Introduction}

The soil-transmitted helminths are a group of parasitic nematode worms causing human infection through contact with parasite eggs or larvae that thrive in the warm and moist soil of the world's tropical and subtropical countries [1].
In order to effectively control STH infection, there is a need for accurate description and understanding of the geographical distribution of infection. The initial difficulty presented by the traditional cartography was one of the reasons for lack of information about the spatial patterns of infection. These difficulties have been dramatically resolved by the advent of 
the easy to use systems that will capture data, store it and analyze it, this include global positioning systems and geographical information systems [2]. The use of geographical information systems, remote sensing and spatial statistics has greatly enhanced the ability to map the distribution of STHs [1, 3]. Many epidemiological studies have been done by examining the stool sample of the inhabitant, these results do not indicate the extent to which the residents are at the risk of parasitic infection but demonstrate the point prevalence of infection within the community sampled [4]. Previous research has reported marked heterogeneity in the pattern of parasite distribution within individuals, households and communities [5]. The use of geographical information systems has now provided a novel understanding of ecology of infection. This has led to the development of low cost ways to identify target populations for treatment $[2,5,6]$. A GIS-based study in a cohort of South African primary school children demonstrated that within a smaller area, there is a pronounced spatial clustering of infection, which according to the authors was strongly influenced by several environmental factors [8]. Previous studies done in Brazil $[9,10]$ and in a rural community in Uganda reported households clustering of helminth infections [11]. A random distribution was reported for hookworm infection in a study done in a rural community of Cote d Ivoire [7]. There is paucity of information on the spatial distribution of STH infection in Nigerian community.

Many communities in developing world are still not planned and social amenities such as market place, town halls and public places are not well catered for because of the government non-involvement in their planning. These factors tend to poses environmental hazards on the development of the communities and the people cultural and behavior attitude. Remarkably few investigations have been able to address spatial determinants of infection within African communities. For example, GIS-based studies in a cohort of South African primary school children have demonstrated considerable spatial clustering of infection within a smaller area, strongly influenced by several environmental factors [8].

In the Nation-wide study done in Nigeria, it was reported that $A$. lumbricoides has the highest prevalence and endemicity followed by hookworm and then T. trichiura, and that the important predictor of their spatial distribution is the day land surface temperature and dense vegetation. [12]. Hence, there is a need for more information on the use of GIS in the description of the spatial distribution of the STH infection in Nigeria communities.

\section{Methods}

\subsection{Study Area}

Igbo-Ora town was divided into six local communities, and each community has a traditional leader referred to as 'Baale' who are identified as Baba-aso of Igbole, Onisaganun of Saganun, Oludofin of Idofin, Olu of Ibeerekodo, Olu of Pako and the overall head, that is, the Kabiyesi is the Olu of Igbo-Ora.

\subsection{House Mapping}

The town was mapped into three density areas: Low density, medium density and high density areas depending on the household clustering in each area. Seven clusters of house density was identified which comprise of 4 low, 2 medium and 1 high density areas. Base on this, $30 \%$ of the household from each density area was randomly selected for the study (Figure 2). Each household in the study was given a code number and individuals in those household was allotted a Personal Identification Code (PID).

A hand-held GeoExplorer Global Positioning System (GPS) receiver was used to calculate the latitude and longitude of each household participating in the study. Reading with a resolution of $2 \mathrm{~m}$ was taken at the front door or as near as possible in order to receive a sufficient satellite reception and an average of 10 readings of the co-ordinate was taken. Map was created using ArcView 3.3 (Environmental System Research Institute Inc., Redland, CA, USA).

Approval for the protocol was obtained from the Ethical Review Committee of the College of Medicine, University of Ibadan, Nigeria with approval number UI/EC/12/0267. (Appendix 1).

\subsubsection{Inclusion Criteria}

(i) The individual enrolled in this study must reside in the selected area over the last 24 months.

(ii) The member of the selected household is willing and able to give consent to the study and in case of a minor, the parent or guardians give consent on his/her behalf.

\subsubsection{Exclusion Criteria}

(i) The individual attend school or work full-time outside the study area,

(ii) Received anthelminthic treatment within the last 12 months.

\subsection{Parasitological Examination}

Following the administration of the questionnaire, a 100 ml wide mouth screw-capped container pre-labelled with the participant PID were distributed to all subjects for the collection of their stool sample the next day. Uneducated participants were asked to give a mark or signs by which they could recognize each child/wards sample bottles. Their ability to recognize the bottle was counter-checked. Each subject was instructed to scoop a thumb size stool, parents and guardians were instructed to monitor their children during the sample collection to ensure that they place their stool samples into the right containers. Both the wet preparation and Kato-Katz techniques were performed. The presence of any parasite was determined using normal saline wet preparation methods, this is necessary to identify parasite when the load is high and also to identify actively motile parasite such as Strongyloides stercoralis. Kato-katz thick smear technique was used as the concentration methods for helminthes except for $S$. stercoralis. For the intensity of infection, quantification of ova/eggs per gram of faeces (epg), the ova was counted per gram of feaces. 


\subsection{Soil Sample Analysis}

Two soil samples were taken from two different locations at $20 \mathrm{~m}$ distance from the entrance of each household according to Stojčeviić et al. [13]. At each site, $500 \mathrm{~g}$ of top soil was taken with a small shovel in the area inside a quadrant of $25 \mathrm{x}$ $25 \mathrm{~cm}$ and $10 \mathrm{~cm}$ in depth. This was put inside a labeled plastic bag and taken to the laboratory [13]. These samples were analysed in the laboratory using saturated $\mathrm{ZnSO}_{4}$ solution in centrifugation floatation method as described by Cheesbrough [14] and modified by Stojčeviić [13].

\subsection{Data Analysis}

All collected parasitological and questionnaire data was double-entered into an SPSS 15.0 database and STATA 12 (Stata Corp., TX USA) software and it was cross-checked. Bivariate analysis was calculated for all variables to ascertain the strength of association between the exposure and the outcome variable, significance was at $\mathrm{p}<0.05$. Multivariate logistic regression was done using selected variables in relation to the presence of STH infection. Chi-square test $p<$ 0.05 was significant.

Prevalence of infection was expressed in percentage, and intensity was measured by egg count per gram (EPG). Spatial Analysis adopted a Bayesian geo-statistical approach incorporating both spatial correlation and non-spatial clustering at a household-level which provide the spatial distribution of the infection in the community.

\section{Result}

\subsection{Households Infection Within Each Community}

Two hundred and thirty six (236) soil samples were obtained from the surroundings of 137 households. Majority of the soil samples were sandy soil 173 (73.3\%) from 91 households, while 36 soil samples from 27 households were mixture of sand and clay soil (15.3\%) and 27 soil samples from 19 households were clay soil (11.4\%).

The prevalence of soil parasite in Igbo-Ora was $27.7 \%$ and the parasite isolated are A. lumbricoides 33 (24.1\%), hookworm $5(3.6 \%)$, Taenia ova $2(1.5 \%)$ and Schistosoma haematobium $1(0.7 \%)$ and S. stercoralis 1 (0.7\%) (Figure 1). The distribution of STH parasites in the soil within the different four communities sampled in Igbo-Ora is in Table 1. Soil samples were collected from between 31 to 38 households in each community and the result showed 16 out of 36 households in Saganun have STH parasite in their surrounding soil, contributing about $11.7 \%$ of the prevalence of soil parasite in Igbo-Ora community, while the least was found in Pako, contributing 4.4\% prevalence to the infection ( 6 out of 38 households). The distribution of parasites in the environmental soil samples was found to be significantly associated with the different community areas in Igbo-Ora. (Chi-square 7.89, p-value 0.048).

\subsection{Human STH Infection Versus Soil Parasite Within a Household}

Human STH infections was found in 57 (41.7\%) out of the 137 households from where soil were sampled. Human STH infection was significantly associated with the presence of parasite in the environmental soil $\left(x^{2} 5.74, \mathrm{p}\right.$-value 0.017$)$. Households with large number of participant were significantly associated with the presence of parasite in the environment soil ( $x^{2} 33.73$ p-value 0.0000$)$.

\subsection{Spatial Distribution of Soil-transmitted Helminths Infection}

Using Moran's index to analyzed the statistical significance of the distribution. Soil-transmitted helminths infection was generally seen to be randomly distributed in Igbo-Ora community. The location specificity was then assessed; the result showed the $\mathrm{z}$-score of 2.3 with p-value $=0.02$ indicating a significant pattern of clustering for $A$. lumbricoides infection within Isale-Oba community, which was the medium density area in the community of Igbo-Ora (Figure 3a). While Ascaris and hookworm infections were randomly distributed in all other communities within IgboOra (Figure 3b).

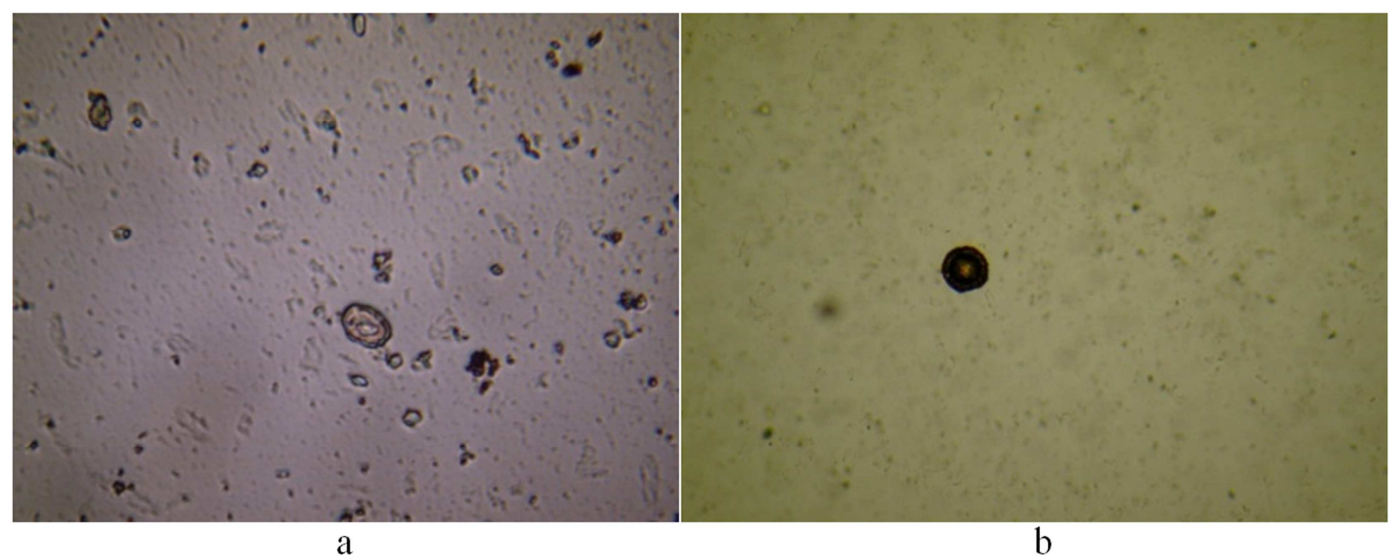

Figure 1. Ascaris and Taenia spp. ova seen in soil samples using Zinc Sulphate floatation method.

a: An ova of Ascaris from soil sample

b: Teania ova from soil sample 


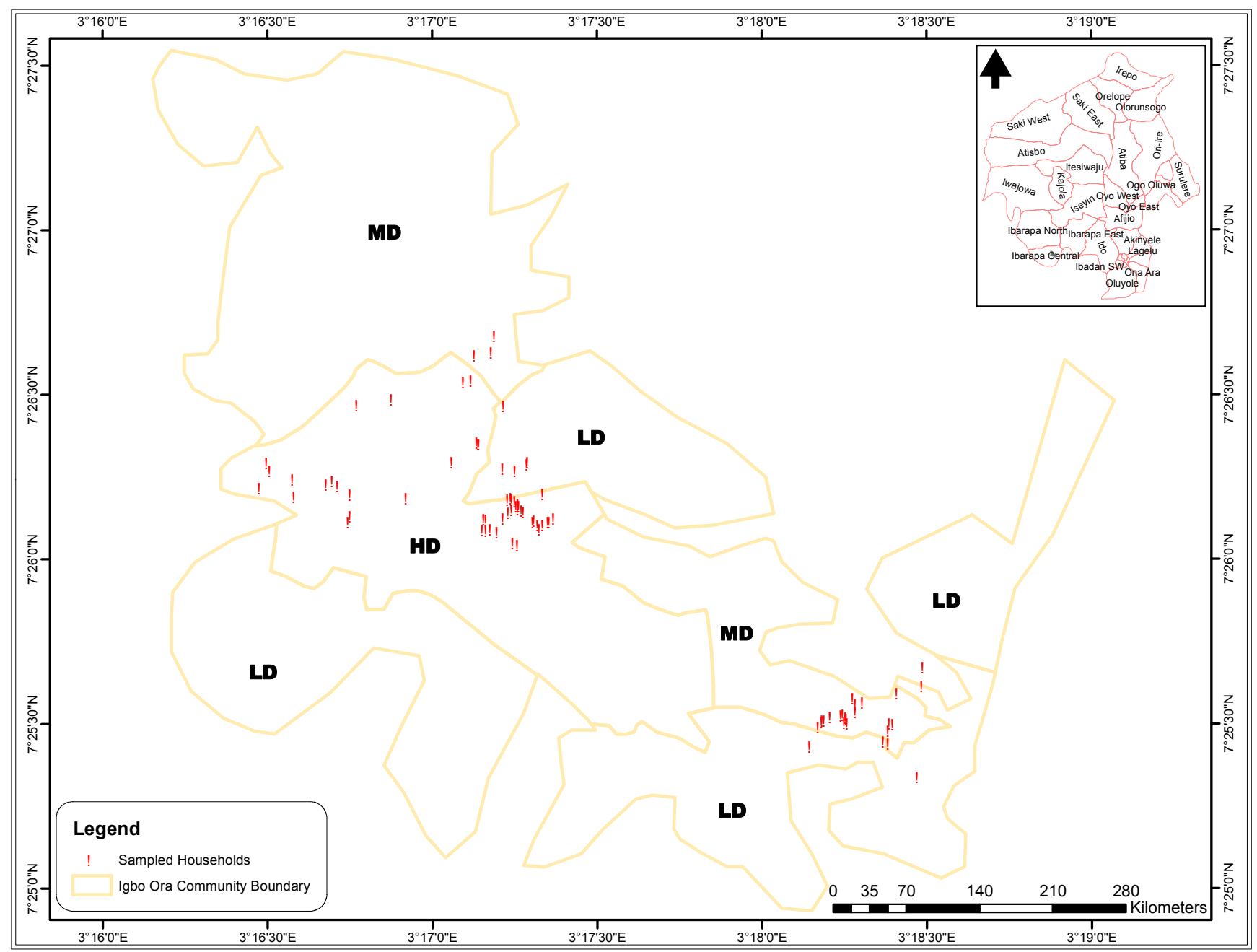

Figure 2. The GIS map of Igbo-Ora showing the hot spot of Soil-transmitted helminths infection in the community.
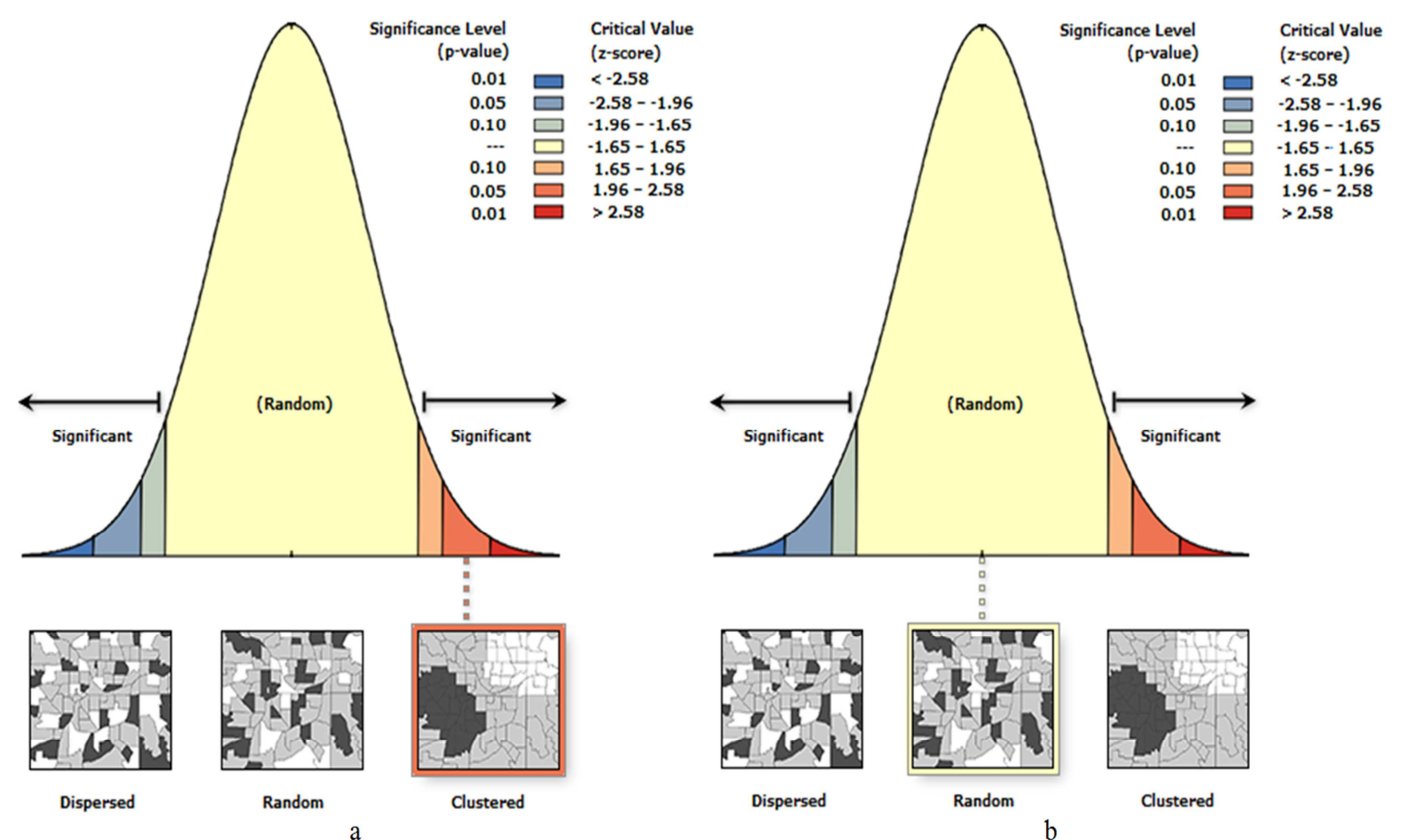

Figure 3. a: Pattern of Ascaris distribution in Isale Oba area of Igbo-Ora; b: Pattern of Hookworm distribution in Isale Oba area of Igbo-Ora. 
Table 1. The Prevalence of soil -transmitted helminth in the environmental soil samples around participants households in the different communities.

\begin{tabular}{|c|c|c|c|c|c|}
\hline \multirow{2}{*}{ Parasite Present } & \multicolumn{4}{|c|}{ No of household per community area where soil samples were taken } & \multirow{2}{*}{ Total } \\
\hline & Igbole & Pako & Isale-Oba & Saganun & \\
\hline Yes & $8(5.8 \%)$ & $6(4.4 \%)$ & $8(5.8 \%)$ & $16(11.7 \%)$ & $38(27.7 \%)$ \\
\hline No & $24(17.5 \%)$ & $32(23.4 \%)$ & $23(16.8 \%)$ & $20(14.6 \%)$ & $99(72.3 \%)$ \\
\hline Total & $32(23.5 \%)$ & $38(27.7 \%)$ & $31(22.6 \%)$ & $36(26.3 \%)$ & $137(100 \%)$ \\
\hline
\end{tabular}

Chi-square $7.89 \mathrm{p}=0.048$.

Table 2. Summary table of Moran index value for the spatial distribution of Ascaris and hookworm in Igbo-Ora.

\begin{tabular}{|c|c|c|c|c|c|c|c|}
\hline & Moran's Index & Expected Index & Variance & z-score & p-value & Type & Pattern \\
\hline Igbole & -0.016884 & -0.0417 & 0.00316 & 0.44092 & 0.65927 & Ascaris & Random \\
\hline Igbole & 0.042867 & -0.0417 & 0.0079 & 0.9511 & 0.34155 & Hookworm & Random \\
\hline Isale Oba & 0.314964 & -0.0435 & 0.02425 & 2.30176 & 0.02135 & Ascaris & Clustered \\
\hline Saganun & -0.02481 & -0.0303 & 0.00783 & 0.06206 & 0.95051 & Ascaris & Random \\
\hline Saganun & 0.022089 & -0.0303 & 0.0079 & 0.58933 & 0.55564 & Hookworm & Random \\
\hline
\end{tabular}

\subsection{Community Specific Associated Risk Factor for STH Infection}

Taking a further look at some of the likely associated risk factors that may be responsible for the clustering of $A$. lumbricoides in Isale-Oba (Table 3). It was observed that only 7 households had access to toilet facilities in the community while the remaining households use bushes around the areas for defecation. Majority of the Ascaris infection within the participant from this same community were of heavy intensity Figure 4.

Table 3. Risk factors and prevalence of STH infection within the participants of Isale-Oba, Igbo-Ora.

\begin{tabular}{|c|c|c|c|c|c|}
\hline \multirow{2}{*}{ Risk factors } & \multicolumn{5}{|c|}{ Intestinal helminthes } \\
\hline & Yes No (\%) & No No $(\%)$ & Total No (\%) & $x^{2}$ & p-value \\
\hline \multicolumn{6}{|l|}{ Sex } \\
\hline Male & $9(18.8 \%)$ & $39(81.2 \%)$ & $48(100 \%)$ & & \\
\hline Female & $16(26.7 \%)$ & $44(73.3 \%)$ & $60(100 \%)$ & 0.94 & 0.23 \\
\hline \multicolumn{6}{|l|}{ Age group } \\
\hline$<1-5$ & $0(0 \%)$ & $2(100 \%)$ & $2(100 \%)$ & & \\
\hline $6-10$ & $2(8.7 \%)$ & $21(91.3 \%)$ & $23(100 \%)$ & & \\
\hline $11-15$ & $9(32.1 \%)$ & $19(67.9 \%)$ & $28(100 \%)$ & & \\
\hline $16-25$ & $14(28.0 \%)$ & $36(72.0 \%)$ & $50(100 \%)$ & & \\
\hline $26-40$ & $0(0 \%)$ & $1(100 \%)$ & $1(100 \%)$ & & \\
\hline $41-50$ & $0(0 \%)$ & $3(100 \%)$ & $3(100 \%)$ & & \\
\hline $51-70$ & $0(0 \%)$ & $1(100 \%)$ & $1(100 \%)$ & & \\
\hline$>70$ & $0(0 \%)$ & $0(0 \%)$ & $0(0 \%)$ & 6.74 & 0.35 \\
\hline \multicolumn{6}{|l|}{ House type } \\
\hline Concrete & $16(21.3 \%)$ & $59(78.7 \%)$ & $75(100 \%)$ & & \\
\hline Mud & $9(27.3 \%)$ & $24(72.7 \%)$ & $33(100 \%)$ & 0.45 & 0.33 \\
\hline \multicolumn{6}{|l|}{ Toilet Access } \\
\hline Yes & $7(25.0 \%)$ & $21(75.0 \%)$ & $28(100 \%)$ & & \\
\hline No & $18(22.5 \%)$ & $62(77.5 \%)$ & $80(100 \%)$ & 0.07 & 0.49 \\
\hline \multicolumn{6}{|l|}{ Toilet type } \\
\hline Water closet & $5(29.4 \%)$ & $12(70.6 \%)$ & $17(100 \%)$ & & \\
\hline Pit latrine & $1(10.0 \%)$ & $9(90.0 \%)$ & $10(100 \%)$ & & \\
\hline Bush around house & $19(23.5 \%)$ & $62(76.5 \%)$ & $81(100 \%)$ & 1.35 & 0.51 \\
\hline \multicolumn{6}{|l|}{ Hand washing habit } \\
\hline \multicolumn{6}{|l|}{ Before eating } \\
\hline Regularly & $21(23.9 \%)$ & $67(76.1 \%)$ & $88(100 \%)$ & & \\
\hline Sometimes & $4(20.0 \%)$ & $16(80.0 \%)$ & $20(100 \%)$ & 0.14 & 0.48 \\
\hline \multicolumn{6}{|l|}{ After the use of toilet } \\
\hline Yes & $14(20.6 \%)$ & $54(79.4 \%)$ & $68(100 \%)$ & & \\
\hline No & $11(27.5 \%)$ & $29(62.5 \%)$ & $40(100 \%)$ & 0.68 & 0.28 \\
\hline \multicolumn{6}{|l|}{ Shoe wearing habit } \\
\hline Regularly & $12(25.5 \%)$ & $35(74.5 \%)$ & $47(100 \%)$ & & \\
\hline Occasionally & $13(21.3 \%)$ & $48(78.7 \%)$ & $61(100 \%)$ & 0.27 & 0.39 \\
\hline \multicolumn{6}{|l|}{ Dirty finger nails } \\
\hline Yes & $6(22.2 \%)$ & $21(77.8 \%)$ & $27(100 \%)$ & & \\
\hline No & $19(23.5 \%)$ & $62(76.5 \%)$ & $81(100 \%)$ & 0.017 & 0.56 \\
\hline \multicolumn{6}{|l|}{ House surroundings } \\
\hline Neat & $17(25.4 \%)$ & $50(74.6 \%)$ & $67(100 \%)$ & & \\
\hline Dirty & $8(19.5 \%)$ & $33(80.5 \%)$ & $41(100 \%)$ & 0.49 & 0.32 \\
\hline
\end{tabular}




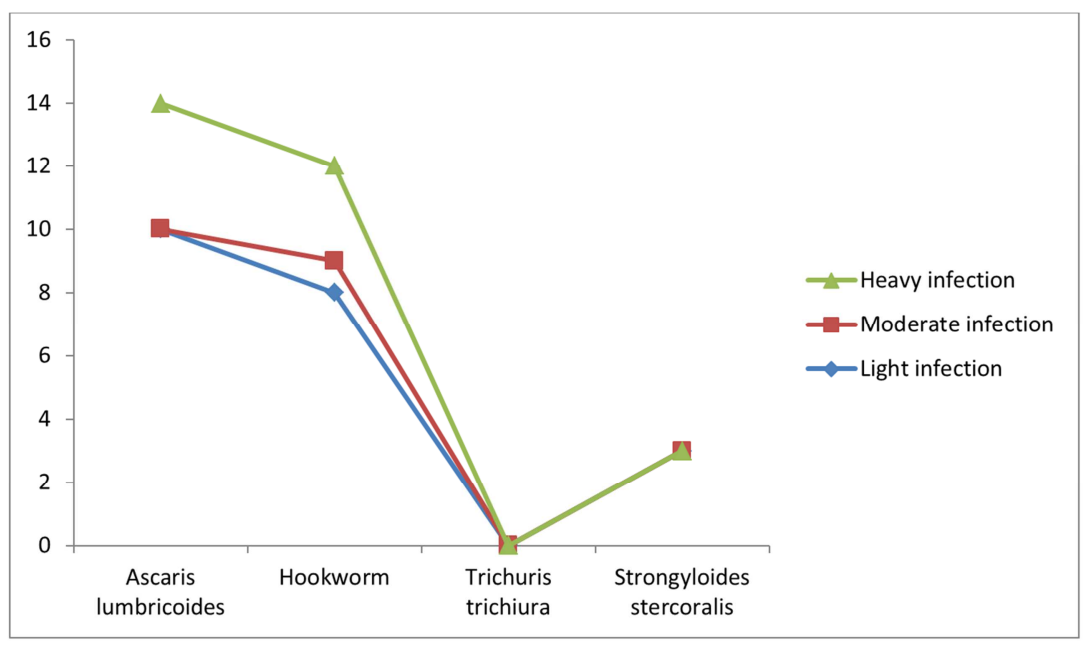

Figure 4. The intensity of STH parasite in Isale-Oba community, Igbo-Ora.

\section{Discussion}

Pullan et al., reported that only few studies within African communities have been able to address the spatial determinants of infections [11]. The presence of soil parasite have been said to be an avenue by which human infection is made possible, because the ova in the soil can be transferred directly to the mouth [15] or to the vegetables and from vegetable to mouth when eaten raw or poorly cooked.

In this study, Ascaris lumbricoides was the major parasite found in the soil followed by hookworm and only one $S$. stercoralis was found, other parasite found include Taenia and $S$. haematobium ova. Similar result was recorded by Adekeye et al [16] in their study done in Ibadan, wherein $A$. lumbricoides was the predominant parasite followed by hookworm and $S$. stercoralis and other parasites aside STH were isolated. The pattern of parasite prevalence was slightly different from what Ogbolu et al [17] recorded in their study in Ibadan wherein hookworm was the most frequently encountered parasite followed by $S$. stercoralis and $A$. lumbricoides was found to be fourth on the line. The reason for the highest prevalence seen may be explained by the structure of the Ascaris ova, wherein the cuticle is thick, it can withstand desiccation and it can survive better in the environment than any other human parasite. Also the season wherein the samples were collected may contribute to the availability of one parasite specie than the others. This is particularly opposite for hookworms (Ancylostoma duodenale and Necator americanus), which have thin-shelled eggs and free-living larvae that are very sensitive to desiccation and cold temperatures. Meanwhile, Trichuris trichiura (whipworm) have no free-living larval stages but rather thick-shelled eggs that allow for prolonged survival under harsh environmental conditions.

The observed prevalence of $41.7 \%$ human STH infection and $27.7 \%$ of STH parasite in the environmental soil is a pointer that there is a need to determine the distribution pattern, exposure factor, the source of infection and possibly the environmental factor responsible for the presence of the infection. The geographic information system revealed that both $A$. lumbricoides and hookworm were randomly distributed in all the sampled areas except for Ascaris that was found to be clustered in medium density area of the community. The observed clustering of Ascaris in this region showed the possibility of a major environmental factor, predisposing individuals in this area to infection. The physical factor that was seen that could be responsible for the unique clustering of Ascaris in this location was the major market. The market, Towobowo by name was, on a normal day, a residential place, but every household and space becomes a market stall every 5 days. This is being patronised by everybody in the community, and there is usually a large influx of people bringing in their farm produce for sales from neighbouring communities. Buyers from other large cities come to take advantage of the cheap farm produce. Data from this community revealed that less than a quarter of the participants from this locality reported to have access to toilet. Less than $16 \%$ had water closet toilet type, $10 \%$ had pit latrine and the remaining $74 \%$ of the participants living in this place defecated in the bush around their homes.

It is of great interest to see that majority of the infection intensity in the same community were of heavy intensity, which may be an indication of continuous exposure and reinfection. The reason for this may be as a result of repeated exposure to the parasite, and non-treatment of the existing infection over a long period of time, which enhanced the chance of increased population of the parasite within the host, since helminth do not multiply within their host. Other studies have also demonstrated that females have heavier worm burden [18]. Considering the individual community and the risk factors of STH infection, the risk factors were not significantly associated with STH infection in this community representing the medium density area. This may be partly due to the none participation of sizeable number of the adult population in the communities, that is, Isale-Oba, and partly due to the small sample size of the participants from this area. This is one of the major limitations of this study.

Another important indicator is that there is no public toilet in this location and the large influx of people into this place 
every five days increased the chance of the people making use of open spaces around the dunghills to increase, thereby making the parasite to be readily available in the community soil, increasing the exposure of the resident to infection. Also, during the rain, the ova in the soil could be washed down to farm land and plants are contaminated with the ova of Ascaris. According to the European Commission, the definition of 'contaminated site': a site where there is a confirmed presence, caused by human activities, of hazardous substances to such a degree that they pose a significant risk to human health or the environment, taking into account land use [19]. Hence the presence of a large volume of excreta in this community, qualify it as being marked as a contaminated area, and therefore, the health of the resident of this area is at risk of STH infection.

\section{Conclusion}

In conclusion, the different distribution pattern displayed by Ascaris and hookworm in this study is an indication that specific approach should be put in place to reduce or curtail the prevalence and intensity of STH infection in our community. More importantly, since the presence of the parasite in the soil is the avenue by which human infection is made possible, then specific measures like provision of public toilets in all public places, such as, markets, hospitals, schools, motor parks, etc., should be considered as an important step to be taken by the government, this will ensure a better health status for all.

\section{References}

[1] Bethony, J., Brooker, S., Albonico, M., Geiger, S. M., Loukas, A., Diemert, D. and Hotez, P. J. 2006. Soil-transmitted helminth infections: ascariasis, trichuriasis, and hookworm. Lancet 367: 1521-1532.

[2] Hay, S. L., Randolph, S. E. and Rogers, D. J. 2000 editors. Remote Sensing and Geographical Information Systems in Epidemiology. Academic Press; London.

[3] Brooker S. and Micheal E. 2000. The potential of geographical information system and remote sensing in the epidemiology and control of human helminth infections. $A d v$. Parasitol. 47: 245-288.

[4] Uga, S., Nagnaen, W. and Chongsuvivatwong, V. 1997. Contamination of soil with parasite eggs and oocysts in southern Thailand. Southeast Asian J Trop Med Public Health; 28 (3) 14-17.

[5] Anderson, R. M. and May, R. M. 1991. Infectious Diseases of Humans. Dynamics and Control. Oxford University Press; Oxford.

[6] Raso, G., Mattys, B., N'Goran, E. K., Tanner, M., Vounatsou, P., and Utzinger, J. 2005. Spatial risk prediction and mapping of Schistosoma mansoni infections among school children living in western Cote d'Ivoire. Parasitology; 131: 97-108 [PubMed: 16038401].

[7] Raso, G., Vounatsou, P., Gosoniu, L., Tanner, M., N'Goran, E.
K. and Utzinger J. 2006. Risk factors and spatial patterns of hookworm infection among schoolchildren in a rural area of western Cote d' Ivoire. Int J Parasitol 36: 201-10. [PubMed: $16259987]$.

[8] Saathoff, E., Olsen, A., Sharp, B., Kvalsvig, J. D., Appleton, C. C., and Kleischmidt, I. 2005. Ecologic covariates of hookworm infection and reinfection in rural KwazuluNatal/South Africa: a geographic information system-based study. Am J Trop Med Hyg 72: 384-391.

[9] Brooker, S., Jardim-Botelho, A., Quinnell, R. J., Geiger, S. M., Caldas, I. R., Fleming, F., Hotez, P. J., Correa-Oliveira, R., Rodrigues, L. C. and Bethony, J. M. (2007) Age- related changes in hookworm infection, anaemia and iron deficiency in an area of high Necator americanus hookworm transmission in south-eastern Brazil. Trans R Soc Trop Med Hyg. 101: 146-154.

[10] Pullan, R. L., Bethony, J. M., Geiger, S. M., Cundill, B., Correa-Oliveira, R., Quinnell, R. J., and Brooker, S. 2008. Human helminth co-infection: analysis of spatial patterns and risk factors in a Brazilian community. PLoS Neglect Trop Dis 2: e352 [PubMed: 19104658].

[11] Pullan, R. 1., Kabatereine, N. B., Quinnell, R. J. and Brooker, S. 2010. Spatial and Genetic Epidemiology of Hookworm in a Rural Community in Uganda. PLoS Negl Trop Dis 4 (6): e713. Doi: 10.1371/journal.pntd.0000713.

[12] Oluwole, A. S., Ekpo, U. F., Karagiannis-Voules, D-A, Abe, E. M., Olamiju, F. O, Isiyaku, S., Okoronkwo, C., Saka, Y., Nebe, O. J., Braide, E. I., Mafiana, C. F., Utzinger, J., and Vounatsou, P. 2015. Bayesian Geostatistical Model-Based Estimates of Soil-Transmitted Helminth Infection in Nigeria, Including Annual Deworming Requirements. PLoS Negl Trop Dis 9 (4): e0003740. doi: 10.1371/journal. pntd.0003740.

[13] Stojčević, D., Sušić, V. and Lučinger, S. 2010. Contamination of soil and sand with parasite elements as a risk factor for human health in public parks and playgrounds in Pula, Croatia. Vet. arhiv 80, 733-742.

[14] Cheesbrough M. District laboratory practice in tropical countries. Cambridge University Press, 2000; 209 (211): 212 215.

[15] Kobayashi A. 1999. Ascaris, Textbook for seminar on parasite control administration for senior officers- A step towards primary health care. Tokyo; 5: 233-242.

[16] Adekeye, T. A., Thompson, E. and Awobode H. 2016. Environmental contamination and public health risk of soil parasite in Ibadan South East Local Government Area, Nigeria. ResearchGate DOI: 10.1080/21658005.2016.1161120.

[17] Ogbolu, D. O., Terry- Alli, O. A., Amoo, A. O. J., Olaosun, I. I., Ilozavbie, G. W., Olusoga-Ogbolu, F. F. 2011. High-level parasitic contamination of soil sampled in Ibadan metropolis. Afr. J. Med. med. Sci. 40, 321-325.

[18] Holland, C. V., Asaolu, S. O., Crompton, D. W., Stoddart, R. C., Macdonald, R. and Torimiro, S. E. 1989. The epidemiology of Ascaris lumbricoides and other soiltransmitted helminth in primary school children from Ile-Ife, Nigeria. Parasitology 99 Pt 2: 275-285.

[19] Science Communication Unit, University of the West of England, Bristol. 2013. Science for Environment Policy Indepth Report: Soil Contamination: Impacts on Human Health. Report produced for the European Commission DG Environment, September 2013. 